
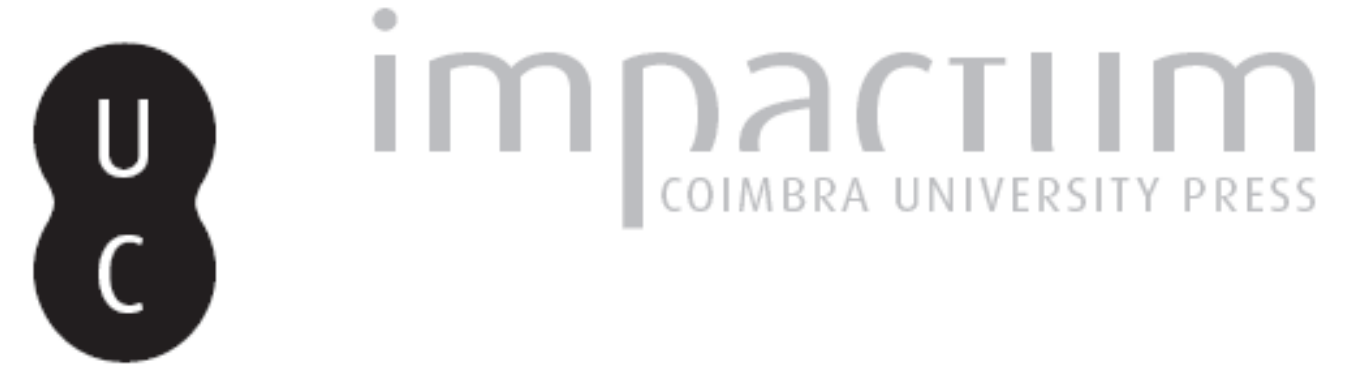

\title{
O filme imortais de Tarsem Singh: uma proposta didática
}

Autor(es): $\quad$ Ferreira, Luísa de Nazaré

Publicado por: Imprensa da Universidade de Coimbra

URL persistente:

URI:http://hdl.handle.net/10316.2/42298

DOI:

DOI:https://doi.org/10.14195/2183-7260_61_11

Accessed : $\quad$ 26-Apr-2023 16:35:36

A navegação consulta e descarregamento dos títulos inseridos nas Bibliotecas Digitais UC Digitalis, UC Pombalina e UC Impactum, pressupõem a aceitação plena e sem reservas dos Termos e Condições de Uso destas Bibliotecas Digitais, disponíveis em https://digitalis.uc.pt/pt-pt/termos.

Conforme exposto nos referidos Termos e Condições de Uso, o descarregamento de títulos de acesso restrito requer uma licença válida de autorização devendo o utilizador aceder ao(s) documento(s) a partir de um endereço de IP da instituição detentora da supramencionada licença.

Ao utilizador é apenas permitido o descarregamento para uso pessoal, pelo que o emprego do(s) título(s) descarregado(s) para outro fim, designadamente comercial, carece de autorização do respetivo autor ou editor da obra.

Na medida em que todas as obras da UC Digitalis se encontram protegidas pelo Código do Direito de Autor e Direitos Conexos e demais legislação aplicável, toda a cópia, parcial ou total, deste documento, nos casos em que é legalmente admitida, deverá conter ou fazer-se acompanhar por este aviso.

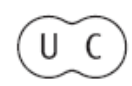




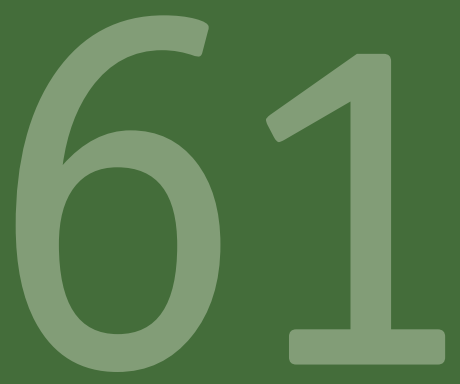

\title{
BOLETIM DE
}

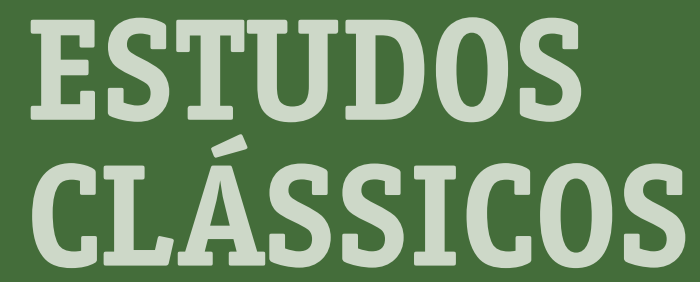

\author{
ASSOCIAÇÃO \\ PORTUGUESA \\ DE ESTUDOS \\ CLÁSSICOS \\ INSTITUTO \\ DE ESTUDOS \\ CLÁSSICOS
}




\title{
O FILME IMORTAIS DE TARSEM SINGH: UMA PROPOSTA DIDÁTICA*
}

\section{THE FILM IMMORTALS BY TARSEM SINGH:}

A DIDACTIC PROPOSAL

\author{
LUÍSA DE NAZARÉ FERREIRA \\ CECH - UNIVERSIDADE DE COIMBRA \\ luisanazare@gmail.com
}

Resumo: Lançada em novembro de 2011, a produção americana Immortals, dirigida por Tarsem Singh, alcançou grande sucesso comercial, mas recebeu críticas negativas a respeito do tratamento da mitologia grega. Numa perspetiva mais moderada, este estudo propõe uma leitura do filme com vista à sua utilização em contexto didático.

Palavras-chave: Teseu; mitologia grega; cinema; recepção.

Abstract: Released in November 2011, the American production Immortals, directed by Tarsem Singh, achieved great commercial success, but received negative reviews regarding the treatment of Greek mythology. From a more moderate perspective, this study proposes a reading of the film in order to its use in a didactic context.

Keywords: Theseus; Greek Mythology; Cinema; Reception.

* Trabalho desenvolvido no âmbito do projeto UID/ELT/00196/2013, financiado pela FCT - Fundação para a Ciência e a Tecnologia. Esta reflexão tem origem numa comunicação apresentada em 25 de janeiro de 2015 no Museu Nacional de Arqueologia de Lisboa, no âmbito das atividades do Grupo de Amigos do Museu, a convite do Dr. Luís Raposo, a quem expressamos o nosso agradecimento. 


\section{O FILME IMORTAIS E 0 INTERESSE PERENE PELA ANTIGUIDADE NO CINEMA}

Dirigida por Tarsem Singh e com argumento dos irmãos Vlas e Charley Parlapanides, a longa-metragem Imortais (Immortals) é uma produção norte-americana inteiramente digital, filmada com cenas 2D e 3D, e foi lançada em novembro de 2011. A opção pelo digital tem sido a tendência de muitos filmes de cinema baseados na Bíblia ou em temas da mitologia e história da Grécia e Roma antigas, como Gladiador, de Ridley Scott, de 2000, que foi pioneiro neste domínio técnico, Tróia, de Wolfgang Petersen, de maio de 2004, Alexandre, o Grande, de Oliver Stone, também de 2004, 300, de Zack Snyder, realizado em 2006 e baseado na novela gráfica de Frank Miller, Confronto de Titãs (Clash of the Titans), de Louis Leterrier, de 2010, que teve em 2012 uma sequela dirigida por Jonathan Liebesman (Wrath of the Titans, Confronto de Titãs 2), e Centurião, de Neil Marshall, também de 2010. O ano de 2014 foi especialmente fértil em filmes de tema bíblico ou clássico produzidos digitalmente: A lenda de Hércules, realizado por Renny Harlin, foi lançado em janeiro, Pompeia, de Paul W. S. Anderson, em fevereiro, 300 - A Ascensão do Império (uma continuação de 300 , que se centra na batalha de Salamina e nas personagens de Temístocles e Artemísia), de Noam Murro, data de março, bem como Noé, de Darren Aronofsky; Hércules, dirigido por Brett Ratner, foi lançado em julho, Hércules Renasce (Hercules Reborn), de Nick Lyon, no mês seguinte e Êxodo: Deuses e Reis, de Ridley Scott, em dezembro. Já com data de 2016 registam-se os títulos Os Deuses do Egito, de Alex Proyas, lançado em fevereiro, O Jovem Messias, de Cyrus Nowrasteh, em março, e Ben-Hur, de Timur Bekmambetov, em agosto ${ }^{1}$.

1 Em 2016 saiu também uma nova versão de Os Sete Magníficos, sob a direção de Antoine Fuqua, um remake da obra homónima de John Sturges (1960). Para um exame das influências clássicas desta película, veja-se o estudo de Rodrigues 2016 sobre a representação da tragédia grega no Western americano. 
Este interesse constante pela representação da Antiguidade no cinema - matéria que tem sido examinada regularmente, com grande rigor e pertinência, nas páginas do Boletim de Estudos Clássicos - constitui uma confirmação absoluta da riqueza inesgotável e perenidade do seu imaginário, que pode ser explorado de forma motivadora nas aulas de cultura clássica. É este o objetivo principal da leitura que propomos de Imortais, que não é de modo algum exaustiva nem deve ser entendida como crítica cinéfila.

Tarsem Singh (n. 1961) é um realizador de origem indiana, que se formou na Califórnia, e dirigiu anteriormente o thriller A Cela (2000) e o drama fantástico A Queda (2006). Em Espelho, espelho meu, de 2012, regressou ao conto clássico de Branca de Neve. Em 2015 dirigiu o thriller de ficção científica Outro/Eu (Self/less). Em Imortais, o ponto de partida é o mito de Teseu, mas a equipa técnica, embora não rejeitando a influência helénica, procurou esclarecer desde o lançamento que esta obra expressa essencialmente a "visão de Tarsem".

Por conseguinte, Imortais tem como personagem central uma figura célebre da mitologia grega, cujos feitos foram equiparados aos de Héracles, tornando-se desde meados do séc. VI a.C. num dos heróis da propaganda política de Atenas (e talvez o mais importante para os atenienses). O Teseu do filme, interpretado pelo ator britânico Henry Cavill, é um camponês da aldeia grega de Kolpos (nome que significa "golfo, braço do mar"), filho de uma mulher solteira (que terá sido violada), e carrega consigo o estigma de ser um filho bastardo. Apesar dessa condição, Teseu tem uma relação muito próxima e afetuosa com a mãe, interpretada pela atriz americana Anne Day-Jones.

De um modo que lembra a educação ministrada por Atena a Telémaco na Odisseia, Teseu cresceu na companhia de um ancião, interpretado pelo ator britânico John Hurt, a quem chama apenas Velho (old Man). Trata-se, na verdade, do deus Zeus que o tem ensinado a pensar e a lutar, a levar uma "vida justa", como ele próprio diz, depositando nele a esperança de se tornar no salvador da Humanidade, decisão que apenas pode ser tomada de livre vontade pelo jovem. 
O filme começa com a apresentação do conflito que vai estar no centro do enredo: Hipérion, o rei malévolo de Heráclion (Creta), interpretado por Mickey Rourke, anseia apoderar-se de uma arma mágica, o chamado Arco do Epiro, que lhe dará o poder de dominar a Humanidade, pois com ele conseguirá abrir a prisão em que se encontram encarcerados os Titãs, vencidos no passado por Zeus e seus aliados. É com uma imagem quase futurista dos deuses condenados ao cárcere ad aeternum, no interior de uma montanha chamada Tártaro, que o filme se inicia. A fim de obter o arco prodigioso que, segundo as lendas, havia sido forjado por Héracles, o rei Hipérion invade com o seu exército um santuário oracular, para encontrar a "profetisa virgem", de nome Fedra, a única de quatro jovens que possui o dom da clarividência, personagem interpretada pela atriz indiana Freida Pinto.

A intriga desenrola-se com o ataque à aldeia de Teseu. Este é feito prisioneiro, situação que o leva ao encontro da profetisa, como estava destinado a acontecer. À semelhança de outras histórias, reais e fictícias, também aqui há um traidor, Lisandro, interpretado pelo ator inglês Joseph Morgan, que se torna escravo de Hipérion, bem como um companheiro intrépido, antigo ladrão, que ajuda Teseu e Fedra a fugirem. Esta personagem de Stavros é interpretada pelo ator americano Stephen Dorff, enquanto o monge do santuário oracular coube ao ator canadiano Greg Bryk. Tal como no mito grego, Teseu também terá de lutar com uma "Besta", um ser cujo físico lembra claramente o Minotauro, no momento em que o jovem encontra o famoso arco mágico. Entretanto, no reino dos deuses, Zeus, interpretado por Luke Evans, impõe a Lei segundo a qual as divindades não podem interferir nos assuntos humanos, uma norma difícil de cumprir, à semelhança do que acontece na Ilíada.

Da equipa técnica de Imortais fazem parte dois produtores - Gianni Nunnari e Mark Canton - que integraram a produção de 300 de Zack Snyder ${ }^{2}$, o que nos dá uma ideia das influências cinéfilas ou do género

2 Sobre este filme, vide Dias 2007 e Loureiro 2007. 
em que se inscreve este filme. Nas várias entrevistas que deram, os produtores e os atores destacaram em especial a originalidade do guião e a qualidade visual do filme. Este parece ser um dos méritos reconhecidos ao realizador, que expressou o desejo de levar até ao espectador uma imagem cinematográfica que se aproximasse de uma pintura de Caravaggio ou dos seus discípulos, embora combinada com algo como o filme Clube de Combate (1999). Na verdade, as tonalidades dominantes em Imortais oscilam entre os tons dourados, ocres e castanhos, contrastando com outros tons mais sombrios ou mais claros, sugerindo a técnica do chiaroscuro. Não passa despercebido, por outro lado, que nalguns cenários surjam pinturas murais inspiradas na decoração de vasos gregos. E se a sequência derradeira, que representa os deuses a lutar nos céus, foi composta como um fresco renascentista, a escultura evocada na parte final do filme, Thésée combattant le Minotaure, foi realizada em 1826 por Étienne-Jules Ramey (1726-1852) e encontra-se hoje exposta no Jardin des Tuileries de Paris.

Os criadores de Imortais também destacaram a importância das cenas de luta - nas quais surge um pouco de todas as modalidades de combate praticadas atualmente - o que se, por um lado, vai ao encontro de um dos temas literários e artísticos mais tratados na Antiguidade, por outro, revela-se claramente uma cedência face aos gostos do público americano e dos espectadores em geral. Na verdade, as cenas de tortura e matança que surgem ao longo do filme, normalmente para reforçar a caracterização psicológica das figuras mais malévolas, embora não pareçam mais abundantes ou cruas do que noutros filmes similares, não deixam de ser particularmente chocantes e excessivas por vezes. Talvez por isso tenha sido classificado como não sendo recomendado para menores de 16 anos.

O produtor Ryan Kavanaugh, numa entrevista que integra os extras da edição portuguesa em Blu-Ray e DVD (Pris Audiovisuais, 2012), ainda que não negue a influência de outras obras, afirma que Imortais não se integra em nenhuma categoria cinematográfica. Ou seja, na 
sua opinião é um filme tão original, no sentido em que não se baseia num livro, numa banda desenhada ou noutro filme, que não se enquadra num género específico. É certo que a estética do filme é uma aposta bastante interessante, assim como o tratamento dos dados da mitologia clássica, mas é inegável a presença de elementos e recursos que já se encontram noutras produções de tema greco-romano como, por exemplo, o ambiente sonoro e a forma como a música (de Trevor Morris) acompanha ou reforça a ação (como acontecia em 300), mas também a construção dos cenários, as cenas de luta, e até os adereços e o guarda-roupa (bastante evocativos de Gladiador). Em suma, embora não se ponham em causa os vários méritos criativos e originais que possui, Imortais não destoa em nada do corpus cinematográfico que se começou a formar desde a obra de Ridley Scott.

\section{A ARQUEOLOGIA DE IMORTAIS OU EM BUSCA DAS SUAS FONTES CLÁSSICAS}

A estilista Eiko Ishioka (1938-1912) ${ }^{3}$ afirma, numa outra entrevista que integra os extras da edição portuguesa em Blu-Ray e DVD, que Imortais apenas aproveita alguns dados da mitologia grega, o que não deixa de ser um dos seus aspectos mais válidos. Ou seja, não se trata de fazer "investigação histórica", como ela nota, mas de criar uma obra artística que retoma o mito de Teseu com "liberdade criativa". Estamos, assim, perante um exemplo do que podemos chamar de revisitação de um mito clássico, um aspecto que é inerente à própria existência do mito que vive, de facto, da sua atualização permanente, embora alguns dos seus elementos possam sofrer um processo de cristalização, como observou o grande especialista Walter Burkert (cf. Burkert 1979: 18).

3 Eiko Ishioka, falecida em janeiro de 2012 vítima de cancro, recebeu um Óscar pelo guarda-roupa de Drácula, de Francis Ford Coppola (1992), e trabalhou em quatro filmes de Tarsem Singh. 
É o caso da morte do Minotauro às mãos de Teseu, que também surge em Imortais, embora as circunstâncias em que ocorre este confronto tenham sido modificadas. Note-se que embora não exista um rei Minos, Hipérion é rei de uma cidade cretense, a "Besta" obedece às suas ordens e a luta com Teseu tem lugar num espaço sagrado chamado Labirinto. Portanto, os elementos principais do mito original foram usados em Imortais de forma coerente.

Como referimos inicialmente, na mitologia grega Teseu destaca-se por feitos que foram equiparados aos de Héracles - como a guerra contra as Amazonas ou contra os Centauros -, chegando inclusive a participar juntos nalgumas aventuras, e tornou-se especialmente importante na Ática, quer em termos políticos quer religiosos, tendo sido instituídos festivais em sua honra (e.g. Oscophoria, Theseia). As fontes literárias mais importantes que nos chegaram sobre a sua lenda são a obra do historiador grego Diodoro Sículo (séc. I a.C.), a Vida de Teseu escrita por Plutarco (séc. I-II d.C.) e a Biblioteca atribuída a Apolodoro de Atenas (séc. II-III d.C.). À semelhança das aventuras de Héracles, as de Teseu foram também temas muito populares na arte grega, em especial na arte da Atenas clássica, como comprovam as pinturas de vasos de figuras negras e de figuras vermelhas (cf. Neils and Woodford 1994). Não é de espantar, portanto, que Teseu se tenha tornado num tema assíduo na cultura ocidental (cf. Harst 2010: 612-615, Martínez Hernández 2012: 31).

No que respeita à sua filiação paterna, a tradição grega preservou pelo menos duas versões: segundo Plutarco (Thes.3.5-6), é filho de Egeu, rei de Atenas ${ }^{4}$; de acordo com o Pseudo-Apolodoro (3.15.7) e Higino (Fab. 37), o seu pai é Poséidon. Em ambas, porém, a conceção de Teseu é ocasional, pelo que é criado apenas pela mãe, um dado que o filme aproveita. Recolhidos das fontes antigas foram também os nomes das personagens (não tanto a identidade), como Etra, mãe de Teseu (segundo

4 O biógrafo de Queroneia mostra conhecer outra versão, segundo a qual Teseu era filho de uma divindade (Thes. 2.1). 
Plutarco, Thes. 3. 2, é filha de Piteu, fundador de Trezena), Fedra (a esposa, na versão de Eurípides), bem como o nome do filho que nascerá, Ácamas (no mito antigo não há referência ao dom da profecia, mas à participação na lenda de Tróia).

Hipérion, ainda que na tradição grega seja o nome de um Titã, ou seja, um dos filhos de Urano e de Gaia, não se terá cruzado alguma vez com Teseu. Portanto, se esta personagem é um elemento original do filme, também o é, em parte, o Arco do Epiro, embora a ideia de um objecto com poderes mágicos não seja estranha à mitologia grega (e.g. o arco de Héracles, usado na Guerra de Tróia, o cinto da Amazona Hipólita, o velo de ouro, as sandálias de Hermes, o elmo emprestado a Perseu). Na Vida de Teseu (6. 2-3), Plutarco escreve, na versão de Maria do Céu Fialho (2008: 44), que: "quando Teseu chegou à adolescência e revelou que, aliada à força física, possuía coragem e uma declarada nobreza de espírito, assim como inteligência e compreensão, então Etra conduziu-o até junto da rocha e, depois de lhe dar a conhecer a sua origem, ordenou-lhe que tomasse os sinais de identificação do pai [a espada e as sandálias de Egeu] e navegasse rumo a Atenas. 3. Então o jovem, agarrando a rocha pela parte inferior, facilmente a levantou (...)". É possível que o passo do biógrafo grego tenha inspirado a cena do filme em que Teseu encontra o Arco do Epiro, igualmente enterrado sob uma rocha.

Portanto, apesar das liberdades criativas, julgamos que há uma grande coerência no tratamento do "material arqueológico", em especial no que respeita à construção do cenário histórico e religioso. De facto, a ação de Imortais situa-se no ano de 1228 a.C., ou seja, na Idade do Bronze, coincidindo quase com a data tradicional da Guerra de Tróia (1250 a.C.) e com o período ainda florescente dos Micénicos. Portanto, como diriam os gregos antigos, a ação decorre exatamente na Idade dos Heróis.

Um tema explorado em Imortais é o confronto entre os que acreditam na existência dos deuses, como as profetisas e Etra, e os descrentes, 
entre os quais se encontram Teseu e Hipérion - que têm outros aspectos em comum -, além dos que confiam sobretudo nas leis e na razão. No que respeita à definição do ambiente religioso, o filme parece receber influências dos Poemas Homéricos e da Teogonia de Hesíodo. Foi este poema que nos transmitiu o longo relato da Titanomaquia (vv. 617-720), a batalha que durou dez anos (Hes. Th. 636), na qual os Titãs lutaram contra a geração olímpica dos filhos de Cronos e Reia, à qual se aliaram os Ciclopes e os Hecatonquiros. Vencidos pelos deuses que combateram ao lado de Zeus, os Titãs foram encerrados num abismo profundo, no Tártaro bolorento, localizado "no interior da Terra" (Hes. Th. 119, 720-725; cf. Ilíada 8. 13, 8. 481), que Hesíodo descreve assim (Th. 726-733), na versão de Ana Elias Pinheiro (2005: 65): “À sua volta ergue-se uma cerca de bronze e, em volta, a noite/ triplicemente lhe cobre a entrada, enquanto à superfície/ crescem as raízes da terra e do mar estéril./ É lá que os deuses Titãs, nas profundezas das brumas tenebrosas,/ estão sepultados, de acordo com os desígnios de Zeus que amontoa as nuvens,/ num lugar húmido, nos confins da terra imensa./ Não podem sair; Poséidon colocou-lhes portas/ de bronze e uma muralha se estende de ambos os lados." No filme, o Tártaro é uma montanha, mas esta descrição, que sugere a ideia de uma prisão metálica, robusta e indestrutível, pode ter inspirado as imagens de abertura de Imortais, que mostram a terrível existência aprisionada dos Titãs.

Muito homérica parece a representação dos deuses e há vários aspectos que, como já referimos, lembram mais a Ilíada do que a Odisseia: o antropomorfismo, a juventude (o que suscitou críticas relativamente à imagem juvenil de Zeus), o aspecto dourado e luminoso, o sofrimento que sentem quando são feridos, os atributos que usam, como o raio e o tridente, as suas discussões acerca da intervenção no mundo dos humanos e da possibilidade de os salvarem da morte, alterando o seu destino, a ira de Zeus sobre um dos filhos, os voos a pique quando se deslocam do céu à terra, a capacidade de assumirem uma aparência 
teriomórfica, como a metamorfose de Zeus em águia, o ambiente marmóreo e sombrio do Olimpo.

Sendo o protagonista um mortal, o título do filme poderá soar estranho (ou irónico), mas na verdade um dos seus temas centrais é a noção de imortalidade - questão que deixou marcas nalguns mitos gregos e que tem sido bastante discutida pelos especialistas (cf. Henrichs 2010). De facto, um dos aspectos singulares do sistema religioso grego é que os deuses não são eternos (têm um princípio, nascem e reproduzem-se) e também não são omniscientes nem omnipotentes (apesar de o seu poder ser superior), embora esta conceção tenha evoluído no tempo. Imortalidade significa na religião grega "viver para sempre". São raros os casos em que uma figura divina abdicou da sua imortalidade e raros são também os humanos ou heróis (seres semidivinos, mas mortais) que a alcançaram. Ulisses rejeitou essa condição, que lhe era oferecida pela ninfa Calipso, em favor do regresso a Ítaca (Od. 5. 203-224). Por sua vez, segundo Hesíodo (Th. 950-955), Héracles tornou-se imortal depois de superar duras provas e tomou por esposa Hebe, a deusa da juventude. Em Imortais, porém, parece que ser imortal significa sobretudo "ser lembrado no futuro pelos feitos praticados", uma noção que não deixa de ser profundamente grega, enquanto a mortalidade dos deuses ${ }^{5}$ é seguramente a ideia mais estranha do filme e uma exceção rara na tradição clássica.

Imortais alcançou um êxito comercial assinalável, mas também recebeu críticas negativas e pouco consensuais (vide infra), quer no que respeita às opções estéticas quer ao tratamento do fundo mitológico e religioso, do qual procurámos dar uma ideia. Cremos que este filme cumpre um dos objetivos essenciais do cinema que é entreter o espectador sem o aborrecer. Em comparação com outras produções de tema clássico de género fantástico, parece-nos ter uma qualidade

5 Na segunda sequência do filme ("Traidor"), Zeus avisa que se algum dos deuses olímpicos interferir na guerra será castigado com a morte, porque os humanos têm de ser capazes de usar o seu livre-arbítrio. 
superior e a interpretação dos atores é convincente. As imagens iniciais do filme são visualmente muito poderosas e interpretam bem as palavras dos poetas gregos. As pitonisas também falam grego, o que enriquece o ambiente arqueológico do filme e tornam a sua caracterização mais consistente. Não obstante os aspectos negativos que possamos reconhecer, notamos em Imortais um equilíbrio saudável entre tradição clássica e liberdade criativa, o que pode ser um ponto de partida interessante para uma discussão mais séria sobre questões diversas da cultura clássica.

\section{BIBLIOGRAFIA}

Burkert, W. (1979), Structure and History in Greek Mythology and Ritual, Berkeley-Los Angeles-London. University of California Press.

Dias, P. B. (2007), “300, filme de Zack Snyder, Kurt Johnstad e Michael Gordon, 2007”, BEC 47: 173-176.

Harst, J. (2010), “Theseus”, in M. Moog-Grünewald (ed.), Brill's New Pauly Supplements I - Volume 4: The Reception of Myth and Mythology. Leiden-Boston, Brill, 611-615.

Henrichs, A. (2010), "What is a Greek god", in J. N. Bremmer and A. Erskine (eds.), The Gods of Ancient Greece. Identities and Transformations. Edinburgh, University Press, 19-39.

Leão, D. F. e Fialho, M. C. (2008), Plutarco. Vidas Paralelas: Teseu e Rómulo. Tradução do grego, introdução e notas. Coimbra, $\mathrm{CECH}$.

Loureiro, J. D. (2007), “Elmo, escudo e lança. O filme 300, de Zack Snyder”, BEC 47: 177-184.

Mariño Sánchez-Elvira, R. M. (1997), “Teseo, Fedra e Hipólito en el Cine”, EClás 111: 111-125.

Martínez Hernández, M. (2012), "La literatura griega antigua en el cine", in G. Santana Henríquez (ed.), Literatura y cine. Madrid, Ediciones Clásicas, 11-65. 
Neils, J. and Woodford, S. (1994), Lexicon Iconographicum Mythologiae Classicae (LIMC). Vol. 7, Zürich-München, Artemis Verlag, s.v. Theseus.

Pinheiro, A. E. e Ferreira, J. R. (2005), Hesíodo. Teogonia. Trabalhos e Dias. Introdução, tradução e notas. Prefácio de M. H. Rocha Pereira. Lisboa, INCM.

Rodrigues, N. S. (2016), “Tragedia griega y Western americano: estudio de cuatro casos", Habis 47: 307- 323.

\section{CRÍTICAS CONSULTADAS ONLINE (ACESSO EM 4/11/2016)}

Brunick, P. (10/11/2011), “It's Dark, Twisted and Unexplainable”: http://www.nytimes.com/2011/11/11/movies/immortals-with-mickey-rourke-review.html

Ebert, R. (9/11/2011), “Immortals": http://www.rogerebert.com/reviews/ immortals-2011.

Gloyn, Liz (7/12/2011), “Film Review: Immortals”: https://lizgloyn.wordpress. com/2011/12/07/film-review-immortals/.

McCarthy, T. (11/10/2011), “Immortals: Film Review”: http://www.hollywoodreporter.com/review/immortals-film-review-260279.

Mignard, F. (14/05/2015), "Le vrai choc des Titans": http://www.avoir-alire. com/les-immortels-la-critique.

Osenlund, R. K. (11/11/2011), "Immortals": http://www.slantmagazine.com/ film/review/immortals.

Oury, A. (22/11/2011), “Les Immortels": http://www.critikat.com/actualite-cine/critique/les-immortels.html.

Sharkey, B. (11/11/2011), “Movie review: Henry Cavill is mighty in 'Immortals"': http://articles.latimes.com/2011/nov/11/entertainment/la-et-immortals-20111111.

Sims, Ch. (15/11/2011), “'Immortals' is an Epic Adventure in Getting It Wrong [Review]": http://comicsalliance.com/immortals-is-an-epic-adventure-in-getting-it-wrong/. 